\title{
Secondary school reform and technology planning: Lessons learned from a ten year school reform initiative
}

Alan Bain

Charles Sturt University

The lessons learned from a decade long, site based school reform project are used to examine the relationship between technology integration and school reform. The nature of the reforms will be described along with implications and conclusions for technology planning. Six key school reform takeaways will be shared that are necessary to build a foundation for successful IT integration.

\section{Introduction}

Despite its immense potential, the role of information technology (IT) in school reform initiatives has received scant treatment in the reform literature to date. This paper describes the lessons learned from a decade long reform initiative that included information technology as an essential component. The discussion of the initiative is situated within the broader conversation about the role of technology in school reform. The paper will describe one way in which a school reform model can create a meaningful role for technology and in doing so significantly alter the process of technology planning in schools. The model and its elements are described, including a summary of existing formative and summative research on its effects. Additional sources are also identified for readers interested in a more detailed description of the model, the design process, and the role of technology in its implementation.

\section{Unrealised potential}

An extensive body of literature has developed over the last two decades that addresses the use of IT in schools and classrooms (e.g., Kulik, 1994; Mann, Shakeshaft, Becker \& Kottkamp, 1999; Marshall, 2002; Schacter, 1999; Sivin-Kachala \& Bialo, 2000; Wenglinsky, 2002). For the purposes of the present discussion, IT can be defined in its most contemporary 
manifestation as networked instructional and multimedia computers, desktop and portable, and the software they can run. This discussion will focus on the software dimension. There is evidence of positive effects for IT in a host of different areas including: motivation and self concept, diversifying the role of the teacher, teacher-student interaction, student achievement, and social growth (Sivin-Kachala \& Bialo, 2000). This evidence exists in hundreds of studies from varied theoretical and methodological perspectives (2002 Education Market Report).

The results of these studies, combined with a broader societal push for placing technology in schools, has stimulated a rapid growth in the deployment of IT. For example, in the US, access levels in schools improved from 39:1 to 6:1 over the period from 1985-1998 (Anderson \& Ronnkvist, 1998). In Australia, the improvement in access levels has followed a similar pattern. According to the NSW Department of Education and Training, student computer ratios have improved from 22:1 in 1995 to 6:1 in 2002 (NSW Department of Education and Training, 2002).

Yet, despite the promise of the IT research and improved user to computer ratios, the actual deployment in secondary schools is disappointing. Studies show an immense gap between the promise of the broader IT research and the day to day reality of computer deployment. For example, in the US, there are over ten million computers in schools, and annual expenditures on technology of around six billion dollars. However, the predominant uses fall into four relatively predictable categories. They are:

1. Separate courses in computer education;

2. Pre-occupational preparation in business and vocational education;

3. Various exploratory uses in elementary classes; and

4. The use of word processing software for students to present work to their teachers (Becker 2001).

Becker studied the survey responses of four thousand elementary and secondary school teachers. He found that only a small minority of secondary schools used technology for acquiring information, analysing ideas and demonstrating and communicating content understanding. Becker's findings are consistent with his earlier work undertaken in 1994 that found low levels of use at the secondary level. In that study, he reported that only a small number of secondary classes in regular subjects (e.g., maths and science) provided students with substantial experience in using computers and that in high school the use is more consistent with computer skills acquisition than as a tool used in other subjects (Becker, 1994). 
A study by Cuban (2001), conducted in Silicon Valley, the home of the technology industry, found less than five percent of high school students had intense technology experiences and where they did, they occurred mostly in non-academic subjects or where students served as part of the school's technical support system. Less than five percent of teachers in that study integrated technology into their regular curricular and instructional routines. Further, when a small percentage of computer using teachers do become serious, they largely maintain existing approaches to classroom practice. This research supports the view that more or even better technology does not necessarily mean more effective or inspired use. Clearly, this is not the kind of deployment that results in major learning impacts.

Abundant availability of a "hard" infrastructure (wiring, machines, software and a growing "soft" infrastructure (technical support and

professional development) in schools in the late 1990's has not led, as expected, to frequent or extensive teacher use of technologies for traditionaltering classroom instruction. (Cuban, 2001, p. 171).

These findings are not confined to the US. The IMPACT 2 study (Harrison et al., 2003) found relatively low levels of computer use in British schools, a finding confirmed by Gipson (2003) who also indicated that the deep embedding of IT in the curricular life of British schools was rare. Angrist \& Lavy (2002) found similar uninspired use in a study of a large 1:1 deployment in Israel. There has not been a recent large scale Australian study of classroom use analogous to Becker's work. However, there is little evidence regarding the way in which technology is planned for and deployed to expect that a different set of circumstances would prevail in the Australian context.

\section{School reform}

Given the international evidence showing both the potential of IT use and the relatively low and uninspired levels of technology deployment in schools, it would seem logical that contemporary school reform initiatives would incorporate information technology as an essential and prominent feature of their models and designs. Surprisingly, this has not been the case. Information technology has not featured prominently in reports of the development, implementation and evaluation of new school design approaches and comprehensive school reform models (e.g., Berends, et al., 2001; Desimone, 2002; Herman et al., 1999). This is especially surprising given the demonstrable potential of technology to improve student achievement and social growth. These most fundamental goals are also central to the rationale for all school reform initiatives and critical considerations in their summative evaluation (Cicchinelli \& Barley, 1999). 
Further, school reform models frequently seek to differentiate themselves from current practice by addressing aspects of schooling that are highly amenable to IT integration (e.g., delivering more effective feedback, diversifying the role of the teacher, and improving curriculum and curriculum management). Yet, despite this apparent synergy, it seems that in the vast majority of cases, the existing potential of technology to leverage and connect these aspects of school reform have not been developed as a deep and integral part of school reform designs.

Unfortunately, major school reform studies describe the same kind of outcomes for reform as Becker (2001), Gipson (2003) and Cuban (2001) described for technology integration, including inconsistent and sporadic adoption (e.g., Berends et al., 2001; Borman et al., 2002; Cook et al., 1999). The explanations offered for these outcomes are also related to similar factors: time, cost, leadership and difficulties associated with curriculum integration. Given the current challenges in both areas (school reform and technology integration), a need exists to look more closely at the connections between the specifics of school reform and IT and the ways in which an interaction between these forces can result in successful innovation with a reciprocal value or benefit.

What follows is a perspective on using a comprehensive school reform approach to bridge the gap between the potential of technology and its current use. The lessons learned from a decade long, site based school reform project at Brewster Academy are employed to examine the relationship between technology deployment in secondary schools, technology planning and broader school reform.

\section{The School Design Model at Brewster Academy}

Brewster Academy is a co-educational, independent (private) secondary school (grades nine through thirteen) of three hundred and fifty students. Two thirds of the students board at the school and enroll from twentyeight states and sixteen countries. Over the last ten years, Brewster has engaged in a comprehensive school reform effort that has resulted in the reform of all aspects of the school's programs (Bain, 1996; Bain, Fallon \& Smith, 1999; Brosnan, 1996; Kavanaugh-Brown, 2000; Dimmock, 2000; McCord, 1999). The tenets, programs, and practices developed and implemented in Brewster's reform program are based upon a comprehensive approach known as the School Design Model - SDM (Bain, 1994). Brewster employed the SDM as a strategic methodology to build a new program. The SDM is targeted at accelerating the growth of students academically and socially, and reflects the sustained systemic effort recommended for major reform efforts (Cicchinelli \& Barley, 1999). 


\section{The School Design Model components}

The SDM is comprised of eight research based school design elements woven together into a coherent design model. The model has been described in considerable detail in Bain (1994; 2000) and Dimmock (2000) and will be overviewed here, with a description of the content and the integration of technology.

\section{Learning statement}

At the core of the design is the development of a learning statement by the school. The learning statement documents the school's values and beliefs as they relate to how the school can best serve its students. The learning statement represents a point of convergence between what is known about the professional practice of education, much of it sourced outside the school in the early phases of the SDM, and the specific needs of the school and its students as represented by stakeholders. The latter represents the context, the needs and drivers in the school setting. The learning statement sets in place what the school will subsequently do about learning.

\section{Body of practice}

The learning statement establishes the term of reference for the most culturally ambitious element of the design, the development of a body of practice. The SDM calls on the school to identify a set of practices and approaches that it believes, based upon its learning statement, will best serve its students. These are practices and approaches that all teachers will master over time. The goal is not to define "the" absolute body of practice. Rather, by identifying and then subsequently clarifying well-founded approaches, a school can build connections to teachers' roles, creating the capacity for differentiated curriculum, and legitimised mechanisms for support and feedback. The body of practice at Brewster Academy, including reference sources for programs and research, can be seen at a website by The Endeavour Group (2001a).

\section{Curriculum}

In the SDM, curriculum is seen to be an interaction of well supported pedagogy, content frameworks, and classroom interaction techniques that allows for the teaching of multiple groups in the same classroom, the adaptation of instruction to deal with individual differences, the integration of instructional technology (e.g., Wang, 1992), and the active engagement of students in the learning process. The SDM curriculum is also based upon a deeper study of fewer subjects (Sizer, 1984) in a four year mastery curriculum that focuses on demonstrable, authentic assessment outcomes. 
The SDM curriculum design is embedded in a suite of curriculum software tools known as the Curriculum Authoring Tools (CATs) (Bain, 1997; Bain \& Huss, 2000). This software represents an elaborated schema for those transactions associated with the design model and implementation of curriculum. Specifically the CATs are designed to integrate contemporary research on curriculum design including frameworks; authentic and portfolio assessment (e.g., Wiggins, 1993, 1998); effective teaching (e.g., Greenwood \& Delquardi, 1995; Rosenshine, 1986; Slavin, 1990); heterogeneous grouping (Wheelock, 1992); and adapting instruction to deal with individual differences (Huck, Myers \& Wilson, 1989). They include tools for curriculum framing, for the design of authentic and curriculum based measurement, for the management of materials, lesson planning and the design of differentiated instruction.

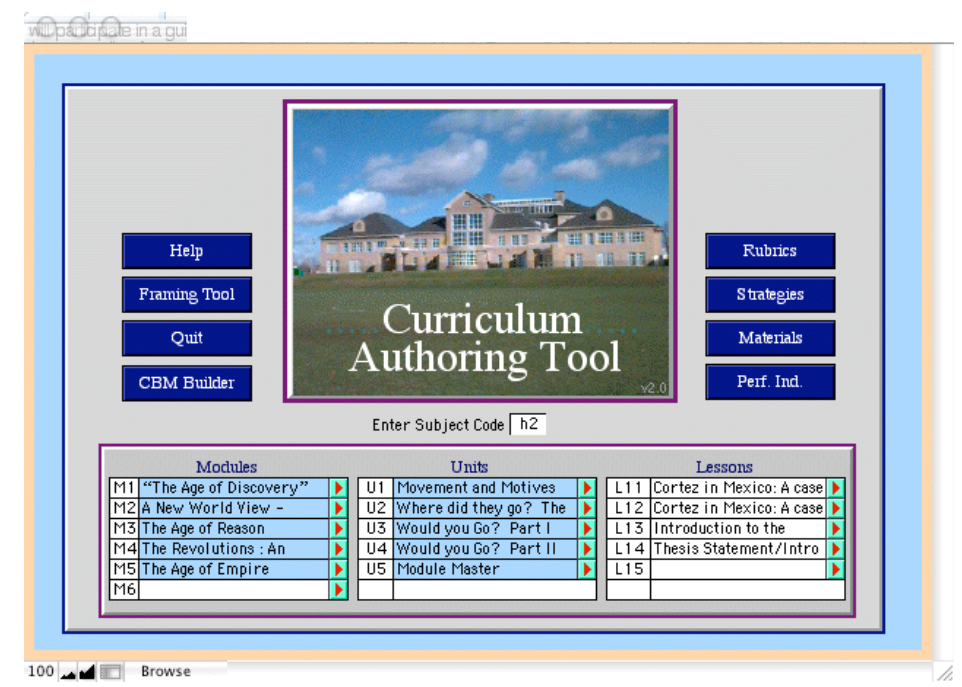

Figure 1: The menu screen for the CATS software.

Further, the CATs are a repository for additional technologies including presentation tools, instructional/content software, simulation tools, and other web based resources. These can be launched from the software on a needs basis for the delivery of classroom instruction. The CATs are employed to translate the school's learning statement into a manageable design and delivery system, with a focus on developing instruction at multiple levels in the same classroom. The goal of the software and the curriculum solution is to flatten the learning curve of faculty in the acquisition of knowledge in all areas associated with curriculum building and implementation. The tools are used to establish a common lexicon of best practice and a common development and delivery methodology. 
In day to day use, teachers employ the tools to design curriculum around existing state and national standards. This includes building the scope, sequence and authentic assessment items for 5-6 week modules of instruction, and building week long units, as well as individual lessons. The lesson planning tools permit teachers to build outcomes for multiple levels of instruction in the same classroom and use lesson design templates that translate those outcomes into classroom practice. At the lesson planning level, the tools also incorporate a feature for managing the activity of different teaching groups, organising the electronic resources required in class (e.g., concept maps, study guides, web pages) and for student homework. Teachers can launch the tools in the classroom to guide their own practice, and display the tools for students to use as a guide for their participation in the lesson.

The tools also serve as a repository for other content related and application software, enabling them to be launched from within lesson plans that frame the teacher's instructional design. For example, a science teacher employing simulation software in a cooperative learning lesson can launch the simulation from within the lesson, ensuring that its use is embedded within the lesson's instructional design and intent. These features of the software reconcile both the design and delivery of instruction, in a single format. They also ensure that pre-exiting application software can be deeply embedded in the actual transactions of the teacher's lesson design. A complete account of the use of the tools including a case study is described in Bain \& Huss (2000).

\section{Training institute}

The fourth solution of the SDM is a pre-service training program to provide faculty with the skills necessary to work in the SDM school. Brewster's training program, known as Brewster Summer Institute, has been conducted for ten years. The program is of six weeks duration and is the entry point to the SDM process for faculty. The content of the SDM training institute is the school's body of practice. All of these skills are taught using the CAT's tools. The training institute is the beginning of a process of formal mentoring by department heads, through team based collaborative decision making and feedback from students, peers, and supervisors with an opportunity for self evaluation.

\section{Human resource mode}

The learning statement, body of practice, curriculum and training program represent the foundation of the SDM's fifth solution, the human resource model. Each of the preceding elements: learning statement, body of practice, and the curriculum design are used to clarify the roles, responsibilities and growth opportunities for faculty and administrators in 
the school, ensuring that they directly reflect the school's approach to meeting the needs of all students. The elements of the human resource model include a set of position descriptions for the roles of teachers and administrators in the school (for a sample position description see Dimmock, 2000). The position description serves as the basis for a career path beginning with Graduate teacher and leading to the role of Senior Master teacher in graduated steps. The transition through each step in the process is based on the submission of an electronic teaching portfolio employed by teachers to demonstrate mastery of each of the areas in the position description.

\section{Collaborative teaming}

The portfolio process represents the culmination of a team based mentoring program, made possible by the sixth solution in the SDM, the collaborative decision making model. The SDM calls for a systemic redesign of all aspects of the school's decision making processes, based upon a devolved collaborative decision making model (Idol, Paolucci-Whitcomb \& Nevin, 1986; Bain, 1993). The school is divided into teams that function as small schools using this model, with a team of teachers responsible for the educational experience of a discrete group of students.

\section{Feedback, reflection and evaluation}

The goal of the SDM's seventh solution is to create powerful natural mechanisms for gathering and sharing information. Feedback and evidence on the growth of the school, a student or a teacher is available all of the time, always serving a formative purpose and readily available for the purposes of summative documentation, program advancement and research. The goal of the evaluation model is to blur the distinction between two well-known evaluation fundamentals, formative and summative evaluation (Scriven, 1967), by creating greater transparency in the provision of feedback. This is accomplished by integrating the evaluation of students, faculty, team and school into a holistic model, enabled by a suite of feedback software tools (Bain, 1997) that are part of the Feedback Tools (Bain, 2000)

These tools were developed by basing upon the learning statement, the body of practice in teaching, curriculum design, collaboration and teamwork, professional growth and the use of technology. The tools have been in use for seven years at Brewster to build collaborative performance reports, gather and analyse surveys and reflections, and conduct classroom observations over a school network (Bain, 2000). Formal evaluation reports are developed in partnership with faculty twice per year, while the process of observing, meeting and mentoring occurs in a natural ongoing cycle. Teachers can go online to observe peers, complete 
surveys, and receive and give feedback to peers and administrators, as well as receive feedback from students (Bain, 2000).

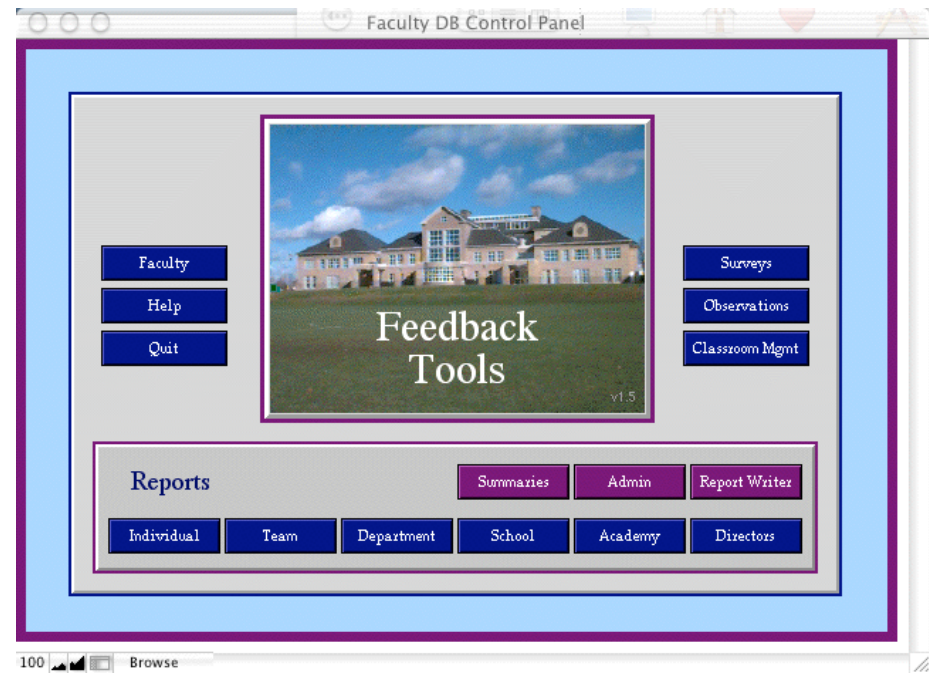

Figure 2: The menu screen for the Feedback Tools

Each tool in the suite is based upon the body of practice, curriculum and professional expectations as defined in the learning statement and articulated in the position description. The feedback model in the SDM uses IT to more directly connect the relationship between teaching and learning, in ways that avoid a focus on any single evaluation methodology or stakeholder perspective (Bain, manuscript submitted for publication).

\section{Technology}

The eighth and final content solution of the SDM is technology. Use of technology in the SDM focuses on the creation of a school operating system (Bain, 1997) that integrates the key transactions associated with the admission of students, the design and implementation of curriculum, the management and implementation of program, the management of human resources, and feedback. The result is a suite of over eighty integrated relational databases that manage the key transactions in the school's learning process, including the curriculum and feedback tools mentioned previously. In practical terms, the tools enable teachers to manage those transactions that are frequently represented in a combination of electronic grade books, daily planners, spreadsheets, word processing documents and classroom noticeboards, in one integrated suite of software tools, resident on the schools network and accessible by every teacher from any computer in the school. Lesson plans and modules of curriculum can be 
directly connected to grading and reporting functions, linking big picture performance standards to student learning. Reflections on teacher classroom performance based upon observations and surveys can be viewed, along with student grades and portfolio items. Students can log on and look at grades and portfolio items, receive feedback on their homework and give feedback to their teachers using the suite of tools.

The technology provides the community with a vehicle to connect those essential functions of schooling that frequently remain disconnected because it is very hard to bring them together in a single format or location. The beliefs, values and pedagogy about feedback, curriculum, teaching approaches, grouping and inclusion that underpin the design are represented in tangible and practical ways in the fields and functions of the tools. As such, each of the relational databases in the system is designed to bring the SDM to the classroom in ways that are accessible for teachers and students. The school's design is a prerequisite for the technology system design. The technology tools sit atop the design, enabling the other seven elements of the design approach to work in practice (Bain, 1999; Bain \& Huss, 2000; Bain \& Smith, 2000).

The overall technology design at Brewster includes a 1:1 teacher and student computer ratio, and a high bandwidth computer network. For the purposes of benchmarking or comparison, the current Brewster program exceeds the requirements identified by the CEO Forum STaR Assessment for a Target Technology School (TTP, 2000). This designation includes those schools where the learning process has been redefined to take advantage of technology, including access levels in excess of 3:1, and a redefined physical layout of classrooms, with online access to digital resources from within and outside of the school. The technology design in the SDM is based on the software system, and is not dependent upon such a ubiquitous technological infrastructure. From a technological perspective, the net result of the introduction of the SDM is the constant pivotal use of technology by teachers and students in all aspects of their engagement with the school.

\section{Existing research and validation}

A number of studies have reported the effects of the SDM on achievement, faculty culture, and technology use. The following is a summary of some of the formative and summative research conducted to date as part of the ongoing validation of the SDM. This includes an eight year longitudinal study of Scholastic Aptitude Test (SAT) performance, that compared the SAT scores of graduating classes for four years prior to the introduction of the design with those who participated over a subsequent four year period. The results indicated an average score 
improvement of ninety-two points for students who experienced the SDM approach over those who participated in a traditional school experience (Bain \& Ross 2000; Bain, manuscript in progress). A longitudinal study of faculty culture indicates that faculty in the SDM approach perceive their experience to be more collaborative, and the culture of the school to be more positive than in forty public and private comparison schools (Bain \& Hess, 2003). Interestingly, the results of this study indicate that faculty believed that, despite the articulation of the school's programs through the application of a design approach, their level of professional autonomy was comparable to those teachers in schools that functioned more traditionally.

A cohort design was employed to study the effects of ubiquitous access to technology on student IT skill. Students who experience the SDM outperform those in a traditional technological program, by over fifty percent in applied IT skills (Bain, Hess, Jones \& Berelowitz, 2000). In a study employing an alternating treatments design, the IT tools were shown to improve student achievement and extend opportunities for discussion beyond the classroom to the home (Bain \& Huss, 2000).

During a decade of implementation, the SDM has resulted in significant improvements in the formative factors associated with the on going conduct of the school. This includes decreasing the ratio of students on an at risk disciplinary status at the end of the year, from one to three to one to ten, accomplished over a decade long period (LeBlanc, 2002; NEASC, 1996). Further, during the same period the number of students recognised for their positive contribution has increased from less than five percent to over sixty percent of the student body (LeBlanc, 2002; NEASC, 1996). The implementation of the SDM has co-varied with high levels of college retention, that have consistently exceeded ninety percent in a longitudina study of the process over a decade (NEASC, 1996; Richardson, 2002). This compares to the US national average of approximately sixty-eight percent for students returning to college for their sophomore year. Over sixty percent of the students enter colleges in the most competitive, highly competitive and very competitive categories.

One of the most pressing issues in comprehensive school reform initiatives like the SDM is the integrity with which these designs are implemented. Implementation has been described as weak and generally incomplete (Berends et al., 2001; Desimone, 2002). To address this issue the SDM gathers 360 degree feedback on the implementation of the design as part of its day to day implementation. Over 15,000 teacher evaluations (by students) have been gathered and analysed over a seven year period. The integrity of implementation of the core teaching practices has been established in over 2000 classroom observations that 
indicate levels of implementation of teaching practice between $86 \%$ and 92\% (Bain, manuscript in progress). The quality of team process has been established through peer, supervisor, and self reflection, and corroborates the finding of the summative study of faculty described previously. Since 1997, nearly 50 Brewster faculty members have made a successful transition in the career path since the full school implementation of the design. Examples of early career and advanced teaching portfolios can be seen at The Endeavour Group (2001b).

\section{Central question}

Visitors to Brewster have expressed considerable interest in the relationship between the comprehensive school reform aspects of the SDM at the school and technology. Their interest can be summarised in the following question: Was the broader reform of curriculum, professional roles and professional development a prerequisite to the design of the software tools and the ubiquitous deployment of technology?

\section{An answer}

The immediate answer to this question is always - Yes, (accompanied by the following explanation): While the school employs many of the subject specific and productivity tools used elsewhere, the key tools for portfolios, curriculum, feedback and professional growth included in the SDM approach are all examples of relational database software. These databases are comprised of fields and tables that contain information. These fields demand definition. That definition emerges from what the school believes.

For example, if we were to build a template in the curriculum tools for designing cooperative learning lessons, it would make sense to first decide on those characteristics of cooperative learning that we believe make a difference in terms of student learning. We could then design those characteristics into the fields in the cooperative learning tool. If we are going to build a feedback tool to reflect on our practice we need to decide what we value in order to frame those reflections. If we are going to build a piece of software for designing curriculum based measures (CBMs) we need to articulate those things that make for effective CBMs when we build such a tool. In the absence of these essential educational features, our technology tools are examples of automation, "electronic stationery," absent of the research that could make our technology distinctively educational.

In the SDM, the definition necessary to create this type of educational technology is part of an emergent process. It emerges from the connection between learning statement, body of practice, curriculum, teamwork, the human resource model, feedback and evaluation, and ultimately 
technology. The technology tools reside on a foundation of research and practice provided by the school's interconnected design elements. This foundation is built from within the school community, as an articulation of what the school believes in practice. The result is an ever evolving professional order with respect to what the school does. This order permits teachers to work together within a common framework or culture of practice (Elmore, 1996; McLaughlin \& Talbert, 2001). It also permits the embedding of what we know about teaching and learning in technology tools that teachers can use every day. This is the opportunity to craft an educational technology as distinct from the downstreaming of technologies from other fields. By articulating what the core activity of the school actually means the conditions are created for reconciling what we know about teaching and learning with a role for technology.

\section{Lessons learned}

The key idea presented here is that the technology integration challenge actually turns out to be a school reform challenge. Given the current literature on school reform, the success of the deployment of IT in schools may turn out to be dependent upon the success of broader school reforms. What then are the essential takeaways about the product of a school reform, based upon the SDM experience at Brewster, that are necessary to build a foundation capable of successful IT integration?

1. The reform must yield a clearly articulated and shared process for classroom learning, the way teachers teach and students learn. This articulation needs to extend beyond the principal level (e.g., being "active learners" or using "best practices"). It needs to drill down to the actual transactions within and across classrooms - what students and teachers actually do in pursuit of learning.

2. IT tools need to support and reinforce those transactions associated with the reform. For example, they need to make it possible, or easier, for teachers to differentiate instruction and teach to multiple groups. IT tools will not always make things easier, but they should make accessible that which may have been viewed as difficult or impossible without them (e.g., differentiating instruction in the secondary classroom).

3. The reforms, including the IT tool development process, need to be emergent, arising from the school's assumptions, beliefs and values. It is much more difficult to deploy educational technology tools meaningfully when their design is based on assumptions (especially educational ones) from developers "far away", whose perspectives are external and frequently alien to the school. This is obviously less the case with content and basic productivity tools. 


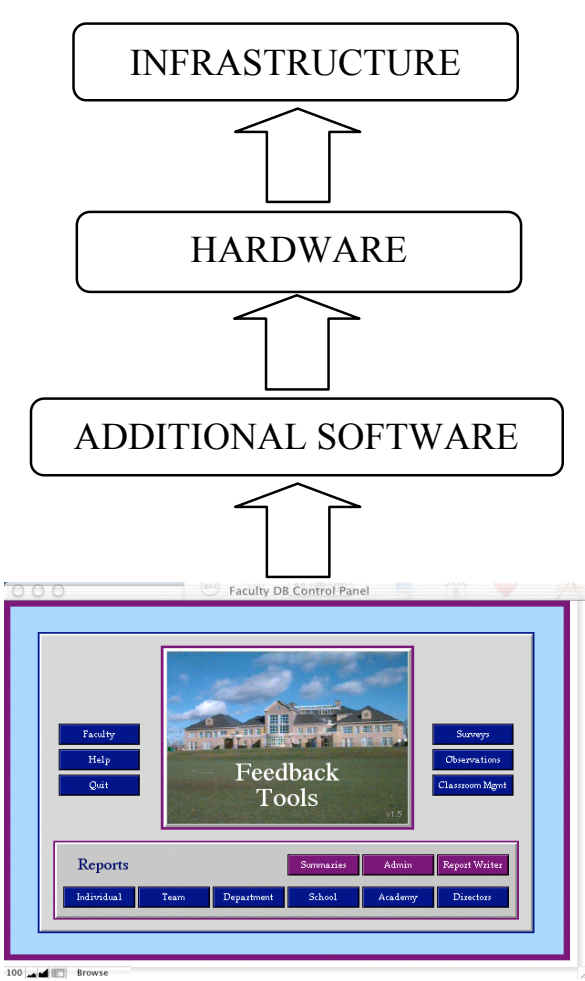

Figure 3: Emergent planning process-schematic form.

4. IT tools need to reflect the deep integration of well-researched practice in the field (e.g., including the characteristics of cooperative learning or differentiated instruction in the design of curriculum and lesson planning tools). This means using tools imbued with what a community believes to be the essential characteristics of cooperative learning, as opposed to downloading a lesson plan from the web that directs teachers to "break students into groups and discuss". It is the presence of this research that makes the IT, Educational Technology (ET).

5. If the technology tools are tightly threaded with classroom practice it becomes possible for teachers, parents and students to learn the reforms through the use of the IT tools. This means that any professional development will blur the distinction between technology training, and training in teaching and learning. Teachers and students can learn about curriculum through the use of curriculum tools and feedback through the use of feedback tools. 
6. The reform footprint when combined with the tools should increase the school's capacity to create, manage and deploy information for the

purpose of individualising the learning experience for all students. The IT tools should open up a genuine potential for knowledge discovery and management in the school. The potential for the latter arises as much from the creation of a shared culture of practice as from the technology, which is a powerful enabler.

\section{Implications for technology planning}

There is an immense upside opportunity for technology planning when a school can bring clarity to what it means by teaching and learning. By crafting a design, it becomes possible to move up to a new level of technology use that directly addresses those curricular, leadership and integration issues that frequently confound technology planning efforts (e.g., Barnett, 2001). Just as a school's design becomes the foundation for the development of IT tools, including those for curriculum or professional growth, the IT tools can, in turn, become the foundation for the technology plan. The plan emerges from the tools.

When IT deployment is closely connected with classroom teaching and learning transactions, a school can build a much clearer picture of where, how and how often technology will be used. This creates an opportunity to be far more specific, focused and fiscally confident when we enter a discussion about hardware, software and infrastructure. Instead of a conversation about counting classes, teachers and students to determine access, the plan would ask the following:

- How often do students need to access their portal and from where?

- What do we need to add to the Curriculum Authoring Tools to make them more accessible for new teachers?

- How can we make tools for writing reflections more efficient?

- How can the curriculum descriptions on the Student Tools be made more dynamic?

- What type and model of computer or network is required to run the tools and associated applications.

Decisions about access, software and connectivity get much easier in this context, because they are all referenced to IT tools that are an embodiment of the design. The gap between the school's vision and curriculum standards and the number of wireless hubs, the number of laptops and the software site license is filled with the school's design. The process is emergent - the design creates the conditions for a genuine educational technology as expressed in its IT tools. Because the tools are an embodiment of what the school is all about, decisions about whether to purchase site 
licenses for Inspiration, Microsoft Office, or AppleWorks, or upgrade the system software are embedded within the school's educational applications, its educational technology. As a result, the plan can answer the following question with a high degree of specificity:

What kind of hardware, software, backroom and physical infrastructure do we need to run our school design?

Clearly, a technology plan extends beyond those relational base tools in the school's operating system. Figure 4 describes the conceptual trajectory from the tools to the broader planning needs for software, hardware and infrastructure.

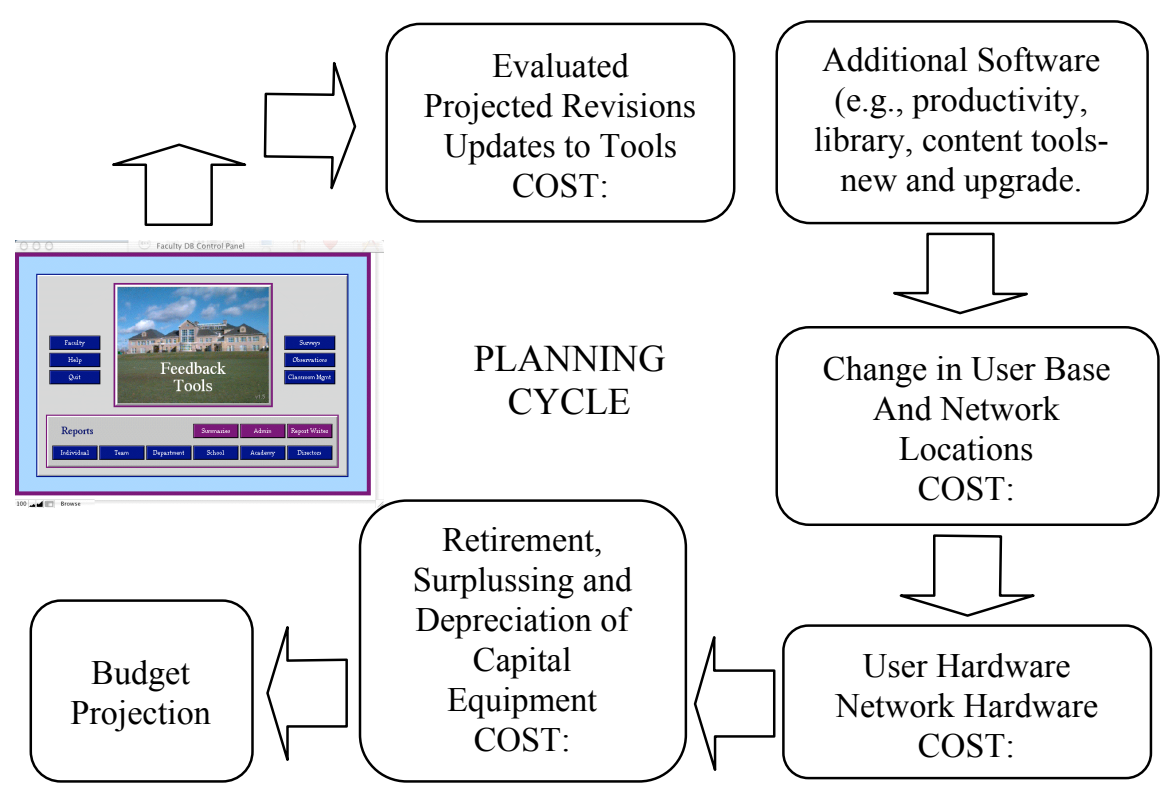

Figure 4: The planning cycle

Consistent with the cycle described in Figure 4, the planning framework begins with the tools and then reconciles hardware, software and infrastructure demands with factors of recycling, surplussing (the retirement of old technology) and dynamic user needs. The tools drive the technology plan. They represent the school's overall design. Everything in the plan embodies everything in the school. When the school decides what it means by teaching, learning and curriculum decisions about access and site licenses and whether to upgrade can occur in a context. 


\section{Conclusions}

Throughout the decade long period during which the SDM was implemented at Brewster, the SDM design group came into contact with many of the large scale computer deployments at school and system level both in the US and internationally. This included schools in both public, private and charter systems engaged in one to one deployments, a number of which exceeded the scope of the Brewster deployment in terms of numbers of computers and total cost. These engagements provided an opportunity to sample a number of approaches to technology integration beyond the Brewster experience.

In nearly every case the results of these efforts were much more akin to the descriptions of Becker and Cuban than the visions of ubiquitous IT use on which they were based. While the schools and systems encountered sometimes faced barriers of time and finance and the different constraints associated with being a public, private or charter school, none of these forces could explain the results. Numbers of these schools were unconstrained financially, or were well-funded startups with few organisational or resistance to change type constraints. Others were engaged in a host of school reform efforts, including new curriculum initiatives, the development of new physical space, and the implementation of new professional development programs. The common feature that united these schools was that none had built a deep, cohesive school wide culture of classroom practice that could catalyse the development of genuine educational technology. These findings, shared anecdotally, are confirmed by an analysis of broader school reform efforts (cited previously in this report) that have failed to show consistent and sustained impact on classroom practice.

The conclusion from these experiences is that the connection between technology and reform is less about whether reform is occurring and more about what that reform yields in terms of a coherent and sustainable change in classroom practice. School reformers generally agree that unless a reform process results in change in the classroom, then there is no reform. Further, that change needs to be evident with integrity across classes and ultimately across schools. The key takeaways from the experience presented here extends this position. To capture the potential of technology the whole of a reform needs to produce a common culture of professional practice. That culture should be the product of research driven beliefs and values. Yet beliefs and values are not enough. They need to be translated into methods and tools used in classes every day. When the latter occurs consistently across classes, teachers and students, the conditions exist for the development of genuine educational 
technologies that can assist teachers, students, parents and administrators. They can also be planned for in a more complete and emergent fashion.

The recent history of technological innovation in schools suggests this should be the decade when it all happens. We spent the nineties putting the four pillars of hardware, software, connectivity and professional development in place (CEO Forum, 2000). We should now be able to accrue the benefit. However, as we have seen from the research described to date, it is unlikely that deep and meaningful use will characterise this first decade of the new millennium.

The evidence provided by existing reform efforts suggests that we need much more than the four pillars to drive meaningful embeddedness. Despite extensive research demonstrating the potential of IT, schools have managed to under-utilise a host of promising technologies because they have been unable to deploy them to truly serve what schools are all about teaching and learning. The gap between the potential of technology as a scalable tool for better practice and the current reality of its deployment in schools may be about a different kind of technology, the technology of school reform. Increasing attention needs to be paid to models for undertaking school reform and the role of educational technologies in the reform process. The model described here represents just one way to do so. At a minimum, those models must produce the articulated classroom impact required to build and deploy genuine educational technologies.

\section{References}

Anderson, R. E. \& Ronnkvist, A. (1998). The presence of computers in American schools. Teaching, Learning and Computing. [verified 19 May 2004]

http:/ / www.crito.uci.edu/tlc/findings/computers_in_american_schools /

Angrist, J. \& Lavy, V. (2002). New evidence on classroom computers and pupil learning. The Economic Journal, 12, 1-31.

Bain, A. (1993). The Brewster Model and collaborative consultation: At the center of school change in independent secondary education. The Consulting Edge, 5(2), $1-6$.

Bain, A. (1994). The School Design Model Future School Institute at Brewster Academy Handbook. Wolfeboro NH: The Endeavour Group.

Bain, A. (1996). The School Design Model at Brewster Academy: Technology serving teaching and learning. Technological Horizons in Education, 23(10), 72-79. [verified 19 May 2004]

http:/ / www.thejournal.com/magazine/vault/ A551.cfm

Bain, A. (1997). Curriculum Authoring Tools [Computer Software]. Wolfeboro, NH: The Endeavour Group.

Bain, A. (1997). School Tools: Management software for the school design model [Computer Software]. Wolfeboro, NH. Endeavour Group. 
Bain, A. (1999). A transformational vision. In T. Hillman \& C. Thorn (Eds), Oh what a web we weave ( pp. 298-305). Gilman, NH: Avocus Press.

Bain, A. (2000). Meaningful evaluations of teachers and teacher education programs. In American Association of Colleges for Teachers Education, Log in or lose out: Technology in 21st century teacher education (pp.244-254), Washington, DC: AACTE Publications.

Bain, A. Emergent Feedback Systems. (Manuscript submitted for publication).

Bain, A. The integrity of implementation of comprehensive school reform initiatives. (Manuscript in progress).

Bain, A. \& Hess, P. T. (2003). School reform and faculty culture: A longitudinal case study. Eric Document Reproduction Service No. ED472 655.

Bain, A., Fallon, M. \& Smith, D. (1999). Designing the Future. In T. Hillman \& C. Thorn (Eds), Oh what a web we weave, 262-272. Gilman, NH: Avocus Press.

Bain, A., Hess, P. T., Jones, G. \& Berelowitz, C. (1999). Gender differences and computer competency: The effects of a high access computer program on the computer competence of young women. International Journal of Educational Technology, 1(1). [verified 19 May 2004]

http:/ / www.ao.uiuc.edu/ijet/v1n1/bain/index.html

Bain, A. \& Huss, P. (2000). The Curriculum Authoring Tools: Technology enabling school reform. Learning \& Leading with Technology, 28(4), 14-17.

Bain, A., Huss, P. \& Kwong, H. (2000). Evaluation of hypertext discussion tool for teaching English literature to secondary school students. The Journal of Educational Computing Research, 23(2), 203-216.

Bain, A. \& Ross, K. (2000). School re-engineering and SAT-1 performance, A case study. The International Journal of Educational Reform, 9(2), 148-154.

Bain A. \& Smith, D. (2000). The School Design Model at Brewster Academy, Part II: Technology enabling school reform. Tustin, CA: Technological Horizons in Education, 28(3), 90-97. [verified 19 May 2004]

http: / / www.thejournal.com/magazine/vault/ A3130.cfm

Barnett, H. (2001). Successful K-12 technology planning: Ten essential elements. ERIC Digest ED457858.

Becker, H.J. (2001). How are teachers using computers in instruction? Paper presented at the meeting of the American Educational Research Association. [verified 19 May 2004] http: / / www.crito.uci.edu/tlc/FINDINGS/ special3 /

Becker, H.J. (1994). Analysis and trends of school use of new information technologies. [verified 19 May 2004] http:/ / www.gse.uci.edu/doehome/ EdResource/Publications / EdTechUse/C-TBLCNT.HTM

Berends, M., Kirby, S. N., Naftel, S. \& McKelvey, C. (2001). Implementation and Performance in New American Schools: Three Years into Scale-Up. Santa Monica, CA: Rand. 
Borman, G.D., Hewes, G.M., Overman, L.T. \& Brown, S. (2002). Comprehensive school reform and student achievement: A meta-analysis. Center For Research on the Education of Students Placed at Risk (No. R-117-D40005). [verified 19 May 2004] http: / / www.csos.jhu.edu/crespar/techReports / Report59.pdf

Brosnan, M. (1996). Make it new: Brewster Academy reinvents itself. Independent School Magazine, Spring, 12-16.

CEO Forum (2000). School technology and readiness report: The power of digital learning: Integrating digital content [verified 19 May 2004]

http: / / www.ceoforum.org/downloads/ report3.pdf

Cicchinelli, L. F., \& Barley Z. (1999). Evaluating for success. Comprehensive school reform: An evaluation guide for districts and schools. Aurora, CO: Mid-Continent Regional Educational Laboratory.

Cook, T.D., Habib, F., Phillips, M., Settersten, R.A., Shagle, S.C., Serdar M. \& Degirmencioglu, S.M. (1999). Comer's School Development Program in Prince George's County, Maryland: A theory-based evaluation. American Educational Research Journal, 36, 543-597.

Cuban, L. (2001). Oversold and underused: Computers in the classroom. Boston, MA: Harvard University Press.

Dimmock, C. (2000). Designing the learning - centered school: A cross-cultural perspective. London: Falmer Press, Garland Inc.

Downs, T., Fluck, A., Gibbons, P., Leonard, R., Matthews, C., Oliver, R., Vickers, M. \& Williams, M. (2001). Making better connections: Models of teacher professional development for the integration of information and communication technology (ICT) into classroom practice. Australian Council for Computers in Education: Canberra: Goanna Print. [verified 19 May 2004]

www.dest.gov.au/schools/publications/2002/MBC.pdf

NSW Department of Education and Training (2002). 11,250 Computers on the way. [verified 19 May 2004]

http: / / www.det.nsw.edu.au/newsroom/yr2002/jun/new_computer.htm

Elmore, R. (1996). Getting to scale with good educational practice. Harvard Educational Review, 66, 60-78.

Gipson, S. (2003). Issues of ICT, school reform and learning-centered school design Full International Practitioner Enquiry Report, National College for School Leadership. http: / / www.ncsl.org.uk/ [article not found 19 May 2004]

Greenwood, C. R. \& Delquardi, J. (1995). Peer tutoring and the prevention of school failure. Preventing School Failure, 39(4), 21-25.

Harrison, C., Comber, C., Fisher, T., Haw, K., Lewin, C., Lunzer, E., McFarlane, A., Mavers, D., Scrimshaw, P., Somekh, B. \& Watling, R. (2003). Impact 2: The impact of information and communication technologies on pupil learning and attainment. [verified 19 May 2004]

http:/ / www.becta.org.uk/page_documents/research/report01.pdf http:// www.becta.org.uk/page_documents/research/report02.pd http: / / www.becta.org.uk/page_documents/research/report03.pdf 
http:/ / www.becta.org.uk/page_documents/research/report04.pdf http:/ / www.becta.org.uk/page_documents/research/report05.pdf

Herman, R., Aladjem, D., McMahon, P., Masem, E., Mulligan, I., Smith O'Malley, A., Quinones, S., Reeve, A. \& Woodruff, D. (1999). An Educators' guide to schoolwide reform. Arlington, VA: Educational Research Service.

Huck, R., Meyers, R. \& Wilson, J. (1989). ADAPT: A developmental activity program for teachers. Pittsburgh, PA: Allegheny Intermediate Unit.

Idol, L., Paolucci-Whitcomb, P. \& Nevin, A. (1986). Collaborative consultation. Austin, TX: PRO-ED.

Integrated Technology Education Group (2002). Facilitating a total system approach to education technology planning and implementation. [verified 19 May 2004] http: / / www.iteg.com/

Kavanaugh-Brown, J. (2000). Putting vision into practice. Converge, 3(2), 56-62. Sacramento, CA. [verified 19 May 2004]

http: / / www.centerdigitaled.com / converge / ?pg=magstory\&id=3585

Kulik, J. A. (1994). Meta-Analytic studies of findings on computer-based instruction. In E. L. Baker and Harold F. O'Neil Jr (Eds), Technology assessment in education and training. Hillsdale, NJ: Lawrence Erlbaum.

LeBlanc, S. (2002). Student conduct. Presentation to Brewster Academy Board of Trustees, Wolfeboro, New Hampshire.

Mann, D., Shakeshaft, C., Becker, J., \& Kottkamp, R. (1999). West Virginia Study: Achievement gains from a statewide comprehensive instructional technology program. [verified 19 May 2004] http:/ / www.mff.org/pubs/ME155.pdf

Marshall, J. M. (2002). Learning with technology: Evidence that technology can, and does, support learning. A white paper prepared for Cable in the Classroom. San Diego,

CA: San Diego State University. [verified 19 May 2004]

http:/ / www.ciconline.com/NR/rdonlyres/emafywh4tgbnmtui6r5qk766nly3uerivatberz5jv3

ahhbvfspifomwvmu2htqfdmfygohcd6hntg/CICReportLearningwithTechnology.pdf

McCord, M. (1999). Exploring the frontier of technology and education reform. New Hampshire Business Review/Tech Net, 12 February, 33-36.

McLaughlin, M.W., \& Talbert, J.E. (2001). Professional communities and the work of high school teaching. Chicago: The University of Chicago Press.

Moll, M. (Ed.). (2001). But its only a tool!: The politics of technology and education reform. Ottawa ON: Canadian Centre for Policy Alternatives.

NEAS\&C (1996). Self-study report for Re-accreditation by the New England Association of Schools and Colleges. Brewster Academy: Wolfeboro.

Richardson, S. (2002). College placement report. Presentation to the Brewster Academy Board of Trustees Meeting, Wolfeboro, New Hampshire.

Rosenshine, B. (1986). Synthesis of research on explicit teaching. Educational Leadership, 43(7), 60-69. 
Schacter, J. (1999). The impact of education technology on student achievement: What the most current research has to say. Santa Monica, CA: Milken Exchange on Education Technology.

Scriven, M. (1967). The methodology of evaluation. In R. E. Stake (Ed), Curriculum evaluation. American Educational Research Association Monograph Series on Evaluation, No.1. Chicago: Rand McNally.

Sivin-Kachala, J. \& Bialo, E. R. (2000). 2000 Research Report on the effectiveness of technology in schools (7th ed). Washington, DC: SIAA.

Sizer, T. (1984). Horace 's compromise: The dilemma of the American High School. MA: Houghton Mifflin.

Slavin, R. E. (1990). Cooperative learning: Theory, research and practice. Englewood Cliffs, NJ: Prentice-Hall.

Stallard, C., \& Cocker, J.S. (2001). The promise of technology in schools: The next twenty years. Lanham, MD: Scarecrow.

The Endeavour Group (2001a). Body of Practice at Brewster Academy. [verified 23 May 2004] http:/ / www.theendeavourgroup.net/SDM/body_of_practice.html

The Endeavour Group (2001b). Early Career and Advanced Teaching Portfolios. [verified 23 May 2004] http: / / www.theendeavourgroup.net/SDM/human_resource.html

2002 Education (2002). In The Software \& Information Industry Association Building the Digital Economy. http:/ / www.siia.net/

Wang, M. C. (1992). Adaptive education strategies. Baltimore, MD: Paul H. Brookes Publishing.

Wenglinsky, H.(1998). Does it compute? The relationship between educational technology and student achievement in mathematics. Princeton, NJ: Educational Testing Service.

Wheelock, A. (1992). The case for un-tracking. Educational Leadership, 50(2), 6-10.

Wiggins, G. (1993). Assessment, authenticity, context and validity. Phi Delta Kappan, 75(3), 200-208, 210-214.

Wiggins, G. (1998). Educative Assessment: Designing assessment to inform and improve student performance. San Francisco, CA: Jossey-Bass.

$$
\begin{aligned}
& \text { Alan Bain, School of Teacher Education } \\
& \text { Charles Sturt University } \\
& \text { Panorama Avenue, Bathurst NSW } 2795 \\
& \text { Phone: +61 } 2 \text { 6338 4133 Fax: +61 } 263384417 \\
& \text { Email: abain@csu.edu.au }
\end{aligned}
$$

